\title{
TRANSECTION OF THE SPINAL CORD DUE TO INJURY AT BIRTH
}

\author{
MARGARET HORAN, M.B., B.S., M.R.C.P., M.R.C.A.P. \\ Medical Superintendent, Adelaide Children's Hospital
}

\begin{abstract}
'In breech deliveries traction on the lower extremities may cause injury of the spinal cord amounting sometimes to physiological transection, even in the absence of actual fracture of the vertebrae.'

This quotation from Holt's Diseases of Infancy and Childhood (1936) has been dramatized in the following case, which is deemed worthy of report on account of the apparent rarity of the condition, the absence of recent reports in British and American literature since those of Crothers and Putnam (1927), and the extreme rarity of a description of certain of the histological changes.
\end{abstract}

\section{Case report}

J.S., a girl aged nine months, was admitted to the Adelaide Children's Hospital in December, 1940, and died at the end of a fortnight.

The obstetrical history was as follows: the mother, a young primipara, at full term required turning of the foetus from a vertex to a breech presentation for treatment of placenta praevia, and delivery was completed under general anaesthesia. The infant weighed eight pounds five ounces, and no unusual difficulty was experienced in delivery. The obstetrician did not consider that undue traction had been required. The baby had appeared quite well immediately after birth, but a gradually increasing paralysis of the legs was noticed two weeks later, and catheterization had to be carried out for retention of urine.

The mother stated that the baby was an active child and moved her head and arms freely, but all her life had never moved her legs very much. She was not able to sit up, and at times was unable to empty her bladder properly.

On examination the child was found to have a normal facial appearance and appeared mentally normal. She moved her head and arms freely and naturally. The upper part of the chest was flattened equally on both sides, the lower ribs were splayed outwards. The upper portion of the chest down to the level of the third ribs moved normally with respiration, but below this level, with each inspiration the chest was drawn inwards and the abdomen bulged. There was a bilateral flaccid paralysis of the abdominal muscles, and the superficial abdominal reflexes were absent. The legs lay motionless and flaccid, and the tendon reflexes were not obtained. Stimulation of the soles of the feet produced a mass reflex. It was not possible to assess sensation over the trunk and limbs. Bed-sores had not developed, and there were no abnormal areas of sweating. From these signs a diagnosis of a transverse myelitis was made although its cause was still obscure.

A skiagram of the spinal column was then taken and did not show any abnormality. Lumbar puncture was next carried out, but the pressure would not register, and only one cubic centimetre of slightly bloodstained fluid could be obtained. Pressure on the veins of the neck did not produce any increase of fluid. There were 192,000 red cells and 300 white cells per c.mm. and the supernatant fluid was a definite yellow colour. These findings suggested a Froin's syndrome and iodized oil injected into the theca in the lumbar region showed a complete block at the level of the body of the fourth dorsal vertebra; a similar injection by puncture of the cisterna magna showed that the upper limit of the block was at the level of the second dorsal vertebra.

The child died of pneumonia and permission was given to examine the spinal cord only. From the level of the second to the fourth dorsal vertebrae in the spinal canal the dura mater could not be separated from the spinal cord; dense adhesions in this area obliterated the normal space between the cord and the dura mater. Above and below this area, which was about one inch long, the normal space was present and the cord appeared normal to the naked eye. There was not any deformity of the spinal column. There was no cystic degeneration of the meninges in the area in question, nor was there any discoloration suggesting altered blood clot.

-A section of the spinal cord taken through the level of the adherent meninges showed a mass of fibrous tissue of some considerable standing, judging by the maturity of the fibrous tissue cells. In the centre of this tissue the central canal of the spinal cord could be identified and scattered elsewhere throughout it were isolated areas of nerve fibre tracts seen in transverse section. There was a certain amount of fat present, mostly at the periphery, and a considerable growth of small vessels extended from the pia into the periphery of the cord. The whole was infiltrated by a number of mononuclear cells, some of which resembled plasma cells. In the whole of this section there was nothing resembling a nerve cell.

A section taken at the lower end of the area in question passed through recognizable spinal cord, but in one posterior horn there were several areas of softening, and judging by one anterior horn, a 188 
considerable loss of nerve cells in the opposite horn. There was no evidence of a pyramidal tract. There was a considerable proliferation of arachnoid cells with thickening of the pia mater so that the normal arachnoidal cavity was practically obliterated.

Below the level of the lesion the sites of the direct and crossed pyramidal tracts contained no myelin sheaths.

No pigmentation was seen in any section.

\section{Discussion}

The unusual finding of complete transection of the spinal cord in an infant was shown in histological section to be traumatic in origin. It was not, however, of the type that follows a haematomyelia as there was no pigmentation, the changes were not cystic nor glial in type and they were not limited to the cord itself. It was not a typical adhesive arachnoiditis as in this condition fibrosis is limited to the meninges and the cord suffers only secondarily the changes of compression. The fact that fibrous tissue was found in the normal position of nervous tissue implies a preliminary breach of the pia mater in this region.

Direct violence as the cause of such changes would necessitate gross local trauma of the vertebrae or the penetration of a foreign body between them. As there was no wound nor deformity in the dorsal region and a skiagram of the spinal column was normal such a cause is discounted.

In adults the upper dorsal region is a most unusual site for injury due to indirect violence, but in injuries at birth, Crothers (quoted by Ford, 1937), in a study of similar cases, states that the lesion occurs almost always in the lower cervical or thoracic segments. He points out that birth injuries of the spinal cord are unlike spinal injuries of any other type in that they are usually due to stretching of the cord and not to compression. The spinal cord is delicate and inelastic, and is relatively fixed by the medulla and brachial plexus above and the cauda equina below. On the other hand the spinal column of infants may be stretched very easily as the ligaments are elastic and the muscles weak. Strong traction in the long axis of the body may therefore be expected to rupture the spinal cord before stretching the spinal column to its limits.

That the injury occurred at birth and not later is supported by the history of an unusual breech delivery in which traction must have been exerted, though it apparently was not severe. It is significant that some disturbance of the lower limbs and bladder was noticed about two weeks after birth.

If such profound injuries can be produced by manipulations that are not considered excessive it is reasonable to suppose that minor injuries are often produced during difficult breech deliveries and are overlooked. It is possible that obscure muscular or skeletal affections of the lower limbs in childhood may be related to birth trauma of this type.

\section{Summary}

A case is described of complete transection of the spinal cord in an infant.

Reasons are given for considering that the condition was traumatic in origin and was produced by traction on the body of the child during an unusual breech delivery.

It is suggested that otherwise obscure diseases of the lower limbs may be related to birth injuries of the spinal cord.

Thanks are due to Sir Trent Champion de Crespigny for permission to report this case and to Professor E. Weston Hurst of the Institute of Medical and Veterinary Science for his help in examining the histological sections.

\section{RefERENCES}

Crothers, B. (1937). Quoted by Ford, F. R., Diseases of the nervous system in infancy, childhood and adolescence, Lond., 775.

_- and Putnam, M. C. (1927). Medicine, Baltimore, 6,41 .

Holt, L. E. (1936). Holt's Diseases of infancy and childhood, New York and Lond., tenth edition, 96. 